\title{
UNA APROXIMACIÓN DEL FONDO COLECTIVO SOLIDARIO POR APORTES AL FONAVI
}

\author{
AN APPROACH OF COLLECTIVE SOLIDARITY FUND \\ FROM CONTRIBUTIONS TO FONAVI \\ Esteban Marino Avelino SÁnchez * \\ Docente Asociado de la Facultad de Ciencias Contables \\ JaIme Bernabé TORRES RAMíreZ** \\ Richard Tipe ToRvisco*** \\ Docentes Contratados de la Facultad de Ciencias Contables \\ Universidad Nacional Mayor de San Marcos - UNMSM / Lima - Perú \\ [Recepción: Setiembre de 2015/ Conformidad: Octubre 2015]
}

\section{RESUMEN}

Por Ley 29625 aprobada mediante referéndum a fines de 2010, se aprobó la devolución de los aportes al FONAVI. A principios de 2012, el Colegio de Abogados del Callao interpone demanda de inconstitucionalidad contra la misma. El Tribunal Constitucional en Sentencia sobre el expediente $\mathrm{N}^{\circ}$ 0007-2012-PI/ TC, octubre de 2012, declara infundada la demanda de inconstitucionalidad e interpreta el artículo $1^{\circ}$ de la Ley indicada; la devolución de los aportes al fondo en forma individual y colectiva; en el primer caso, las contribuciones realizadas por los trabajadores, en el segundo caso, las contribuciones efectuadas por sus empleadores, el Estado y otros, lo que denomina "fondo colectivo solidario". Por tanto, el problema consiste en cómo separar el fondo colectivo solidario cada mes y cada año de la recaudación total de los aportes al FONAVI, obtenida en cada periodo señalado. De noviembre de 1993 a agosto de 1998 discriminando los montos recaudados por la SUNAT se obtiene 2129 millones de dólares en 59 meses, de lo cual resulta un promedio mensual superior a 36 millones de dólares; los aportes al FONAVI de los empleadores habrían superado los 4 mil millones de dólares.

\section{Palabras clave:}

Fondo colectivo solidario; aportes al FONAVI de los empleadores; naturaleza jurídica de los aportes al FONAVI; naturaleza jurídica del tributo contribución; recaudación total de los aportes al FONAVI.

\begin{abstract}
By the law 29625 approved by referendum in late 2010, the return of contributions to FONAVI was approved. In early 2012, the Bar Association of Callao put an unconstitutional claim against it. The Constitutional Court on the judgment of File No. 0007-2012-PI / TC, October 2012, declared the unconstitutional claim unfounded and interprets Article 1 of the stated Act; the return of contributions to the fund individually and collectively, in the first case the contributions made by workers, in the second case the contributions made by their employers, the state and others, what is called "collective solidarity fund". Therefore, the problem is how to separate the collective solidarity fund every month and every year from the total collective contributions to FONAVI obtained in each period. From November 1993 to August 1998 discriminating the amounts collected by the SUNAT, 2,129 million is obtained, in 59 months, resulting in a monthly average of over \$ 36 million; the FONAVI contributions to employers would have exceeded the four billion dollars.
\end{abstract}

\section{Keywords:}

Collective solidarity fund; FONAVI contributions to employers; legal nature of the contributions to FONAVI; legal nature of the tax contribution; total collection of contributions to FONAVI.

\footnotetext{
* Magíster en Contabilidad con mención en Auditoría. Contador Público y Economista Colegiado. Email: estebanavelino@gmail.com

** Lic. Investigación Operativa, Colegiado en el COMAP. Email: jbtr777@gmail.com

*** Lic. Investigación Operativo. Email: richardtipe@hotmail.com
} 


\section{INTRODUCCIÓN}

El concepto "Fondo colectivo y solidario" aparece en la Resolución del Tribunal Constitucional en el expediente $\mathrm{N}^{\circ}$ 0007-2012-PI/TC del 26 de octubre de 2012, para designar los aportes al FONAVI realizados por los empleadores (y otros, no trabajadores), cuya contribución al fondo ha sido, mayormente, cuatro veces la de sus trabajadores. Este fondo, consecuencia de la interpretación del artículo $1^{\circ}$ de la Ley 29625 , será destinado - dice el Tribunal- para satisfacer en forma colectiva las necesidades de viviendas y servicios conexos de los trabajadores que aportaron al FONAVI que así lo requieran; la cuantificación del mismo se justifica para prevenir exacciones predestinadas, luego utilizadas o malgastadas en necesidades diferentes a las que motivaron la exacción, a la postre una nueva deuda pública interna olvidada, allí reside la importancia del tema de este artículo.

Tiene como antecedente el artículo: "Devolución de aportes al FONAVI otra deuda pública olvidada del Gobierno peruano", publicado en la edición anterior de la Revista de Investigación Quipukamayoc, en el cual se da cuenta del monto de las devoluciones individuales, en muchos casos mayor de 15 mil nuevos soles. Sin embargo, el Gobierno peruano viene devolviendo montos ridículos, sin sentido económico, como el caso ocurrido el 29 de octubre de 2015: un fonavista cobró solo 12 nuevos soles, lo que fue transmitido por las radios de la capital del Perú.

Estimar el monto del fondo colectivo y solidario es el objetivo de este artículo. Del periodo 1993 a 1998 existe la información recaudada por la SUNAT, del periodo 1979 a 1992 la información estaría dispersa o habría desaparecido; el Banco de Vivienda del Perú como el Banco de Materiales que manejaron directa o indirectamente los recursos del FONAVI, el primero fue desactivado por razones de política económica, y la segunda institución quebró; en algún lugar estarían los archivos o al menos parte de ellos. Por el lado de los empleadores muchas empresas privadas quebraron, las empresas públicas fueron privatizadas, muchos organismos del sector público desactivados o simplemente no pagaron los aportes al FONAVI que les correspondió como empleadores.
En esta situación; sin embargo, si se puede estimar con base a la información obtenida del periodo 1993 a 1998, los porcentajes de aportes al FONAVI de 1979 a 1992 y aplicando supuestos se logra el objetivo de este trabajo.

A continuación, se desarrolla este trabajo en cinco acápites: ¿Qué es el fondo colectivo y solidario?; la naturaleza jurídica del tributo contribución según el Tribunal Fiscal; realidad fáctica de los aportes al FONAVI, naturaleza jurídica de los aportes al FONAVI según el Tribunal Constitucional; ¿cómo determinar el fondo colectivo solidario?, y finalmente, se presentan las conclusiones y las referencias bibliográficas.

\section{¿QUÉ ES EL FONDO COLECTIVO Y SOLIDARIO?}

El Tribunal Constitucional a través de dos Sentencias en los expedientes $\mathrm{N}^{\circ}$ s 01078-2007 y 03283-2007-PA/TC, del 3 de setiembre de 2007, se pronunció sobre la naturaleza jurídica de los aportes al FONAVI, que se trata de un fondo de carácter privado. Por lo tanto, legitimó la devolución reclamada por la Asociación Nacional de Fonavistas de los Pueblos del Perú (ANFPP).

Por Ley 29625 aprobada mediante referéndum, publicada el 8 de diciembre de 2010, se aprobó la devolución de los aportes al FONAVI a todos los trabajadores que se les descontó de sus remuneraciones; así mismo, el abono a favor de cada trabajador beneficiario, los aportes de sus respectivos empleadores, del Estado y otros aportantes al FONAVI, en la proporción que les corresponda (artículo $1^{\circ}$ ). El Colegio de Abogados del Callao, el 10 de febrero de 2012, interpone demanda de inconstitucionalidad contra la Ley indicada; alega que contraviene los principios del presupuesto público.

El Tribunal Constitucional mediante Sentencia en el expediente $\mathrm{N}^{\circ}$ 0007-2012-PI/TC, de fecha 26 de octubre de 2012, declaró infundada la demanda de inconstitucionalidad e interpretó el artículo $1^{\circ}$ de la Ley 29625, respecto a la devolución de los aportes de sus respectivos empleadores y otros, en la proporción que les corresponda debidamente actualizados, la que se destinaría a un fondo colectivo y solidario para 
satisfacer necesidades de vivienda de los fonavistas que lo requieran por su falta de acceso a este derecho fundamental, dice el Tribunal.

En consecuencia, el fondo colectivo y solidario está constituido por los aportes realizados al FONAVI de los empleadores y otros, señalados en los literales c, d y e del artículo $2^{\circ}$ de la Ley 22591. ¿Cómo se determina el fondo colectivo solidario?, en este artículo damos la respuesta a esta interrogante, antes cabe recordar la naturaleza jurídica de la contribución por aportes al FONAVI efectuada por los juristas.

\section{LOS APORTES AL FONAVI DE LOS EMPLEA- DORES, SEGÚN EL TRIBUNALFISCAL}

Algunos juristas como el Tribunal Fiscal y los Magistrados del Jurado Nacional de Elecciones, conforme a la doctrina tributaria, la definición contenida en la Norma II del Título Preliminar del TUO del Código Tributario ${ }^{1}$ y la hipótesis de incidencia ${ }^{2}$; sostienen que los aportes al FONAVI de cuenta propia de los empleadores no califican como contribución sino, como impuesto.

Oscar Picón y Sonia Dávila (2007), parafraseando el concepto contribución de la Norma II del Título Preliminar del TUO del Código Tributario, cuya obligación tiene como hecho generador beneficios derivados de la realización de obras públicas o de actividades estatales en beneficio de los contribuyentes, como las contribuciones de seguridad social y de mejoras, dicen: "El monto de la contribución, por su destino y por el beneficio brindado, no debe ser superior a este ni al costo de la obra pública o actividad estatal" (p. 2).

El recurrente en el dictamen 053 de la RTF JOO N0523-4-1997 alega: "En derecho las instituciones (jurídicas) se identifican en razón a su esencia y no en función al nombre que se les asigne, ya que lo contrario llevaría admitir que el nombre que (se) las atribuye prima sobre el contenido jurídico" (RTF, 1997, numeral II - quinto párrafo). El quinto considerando de la misma RTF dice: de dicha norma se desprende (alude a la Ley 26233), respecto de la contribución al FONAVI de cuenta propia bastaba que un empleador se encuentre obligado a pagar remuneraciones a sus trabajadores dependientes para que automáticamente quede afecto a dicho tributo, sin que a cambio reciba o haya recibido beneficio alguno derivado de la realización de obras públicas o de actividades estatales. Por ello, el Tribunal Fiscal revoca la Resolución $\mathrm{N}^{\circ}$ 015-4-05227/SUNAT de fecha 29 de febrero de 1996, dejándose sin efecto la cobranza de la deuda impugnada; sentando jurisprudencia de observancia obligatoria en beneficio de las universidades y demás centros de educación. Según el Tribunal Fiscal, los demás empleadores debían continuar pagando los aportes al FONAVI de cuenta propia pero no como contribución sino como impuesto.

\section{REALIDAD FÁCTICA DE LOS APORTES AL FONAVI}

Los recursos del FONAVI, de acuerdo con los artículos $1^{\circ}, 22^{\circ}, 24^{\circ}$ y $17^{\circ}$ del Decreto Ley 22591 , debieron destinarse para construir viviendas a fin de reducir el déficit habitacional de los trabajadores aportantes al fondo: venta o alquiler de viviendas o préstamos para la ampliación o mejoramiento de viviendas. El artículo $26^{\circ}$ de la misma Ley exime, después de 5 años, de los aportes al FONAVI; a los que acrediten ser propietarios de vivienda financiada con recursos distintos a los del fondo aludido y al cónyuge de menor ingreso cuando ambos cónyuges coticen. La intención del legislador, sin haberlo declarado, habría sido la cotización al fondo de por vida, lo que es un despropósito; porque los que podían acceder a una vivienda con préstamos del FONAVI tenían que amortizarlo mensualmente en 25 años y continuar cotizando al fondo; lo que implica doble pago para satisfacer la misma necesidad.

\footnotetext{
1 La norma señalada clasifica los tributos en: a) impuestos, cuyo pago no origina una contraprestación directa a favor del contribuyente por parte del Estado; b) contribución, cuya obligación tiene como hecho generador beneficios derivados de la realización de obras públicas o de actividades estatales y; c) tasa, cuya obligación tiene como hecho generador la prestación efectiva por el Estado de un servicio público individualizado en el contribuyente. Este tributo, a su vez, se clasifica en arbitrios, derechos y licencias.

2 La cual divide a los tributos en: a) vinculados (contribuciones y tasas), cuando el nacimiento de la obligación tributaria está vinculado a una actuación estatal, un acto jurídico o material del Estado como una obra o servicio público o una consecuencia de él y; b) no vinculados (impuestos), cuando el nacimiento de la obligación tributaria está vinculado a la actuación directa e indirecta del Estado.
} 
Peor todavía cuando la mayoría de aportantes al FONAVI no podían acceder a las viviendas construidas con recursos del mismo por limitación de la oferta, bajas remuneraciones de los aportantes, reorientación de sus recursos del fondo para necesidades de infraestructura social de poblaciones vulnerables no aportantes al fondo, administración deficiente y hasta fraudulenta, como la desaparición de muchos expedientes en el Banco de Materiales ${ }^{3}$.

El Decreto Ley 25520, de fecha 27 de mayo de 1992, dice: "Los recursos del FONAVI serán destinados primordialmente a financiar obras de infraestructura sanitaria; electrificación de asentamientos humanos; construcción, ampliación y refacción de centros comunales y recreativos en zonas rurales y urbano marginales; proyectos de destugurización de viviendas; $y$, la pavimentación y/o acondicionamiento de vías locales e interdistritales", con lo cual las universidades y demás centros educativos obtuvieron (sin haberlo pedido) los argumentos jurídicos contundentes para poner en evidencia la inaplicabilidad de la "contribución" al FONAVI de cuenta propia. Sin embargo, no habría afectado sensiblemente la recaudación.

Por Ley 26233, de fecha 13 de octubre de 1993, vigente a partir del 1 de noviembre del mismo año, se estableció una nueva estructura para las contribuciones al FONAVI: a) $6 \%$ a cargo de los empleadores sobre las remuneraciones mensuales abonadas a sus trabajadores (aumentó a 9\% a partir de agosto de 1995, disminuyó a 7\% en enero de 1997 y 5\% en agosto de 1997), b) 3\% a cargo de los trabajadores dependientes sobre las remuneraciones mensuales percibidas (fue suprimida a partir de agosto de 1995) y, c) 3\% la contribución obligatoria de los trabajadores independientes sobre sus ingresos mensuales por trabajo (no se aplicó por falta de reglamentación). Por lo tanto, los aportantes al FONAVI a partir de noviembre de 1993, fueron del empleador y trabajador dependiente (hasta julio de 1995).

Por Ley 26903, de fecha 17 de diciembre de 1997, se modificó los artículos $1^{\circ}$ y $2^{\circ}$ de la Ley 23220 (Ley del Banco de Materiales-BANMAT de 1980) y facultó al BANMAT a colaborar en la solución del problema de vivienda de los centros poblados (...), así como del equipamiento de la microempresa. Por Ley 26969, del 24 de agosto de 1998, se sustituye a partir del 1 de setiembre del mismo año, la "contribución” al FONAVI por el Impuesto Extraordinario de Solidaridad, destinado preferentemente a las obras antes financiadas con recursos del FONAVI; se dispone la liquidación del fondo y la desactivación de la UTE-FONAVI. Por Ley 27677, del 1 de marzo de 2002, se dispone que los recursos provenientes de la liquidación del FONAVI sean transferidos al Ministerio de Economía y Finanzas, para financiar la construcción de viviendas de interés social, remodelación y ampliación de casa única.

Considerando la definición de la Norma II del Título Preliminar del TUO del Código Tributario y la hipótesis de incidencia, los recursos a cuales recurre el Tribunal Fiscal, los aportes al FONAVI de los trabajadores, tampoco califican como contribución sino como una imposición arbitraria, sin ningún beneficio para la mayoría de aportantes.

\section{NATURALEZA JURÍDICA DE LOS APORTES AL FONAVI, SEGÚN EL TRIBUNAL CONSTITUCIONAL}

Las Sentencias del Tribunal Constitucional en los expedientes $\mathrm{N}^{\circ} \mathrm{s}$ 01078-2007-PA/TC y 03283-2007$\mathrm{PA} / \mathrm{TC}$, de fecha 3 de setiembre de 2007, dicen: "El FONAVI es administrado por una persona jurídica (Banco de la Vivienda) diferente al Estado y no está destinado a la realización de obras públicas o actividades estatales, más bien se trataba de un fondo para viviendas de los trabajadores, actividades y obras de carácter privado (...), la ley (22591) en examen no cumple con el principio de legalidad, pues no contiene en forma expresa la voluntad del legislador de crear un tributo (...; por ello y otras consideraciones), las contribuciones de los trabajadores al FONAVI no son impuestos desde el 30 de junio de 1979 hasta el 31 de agosto de 1998”. El Tribunal Constitucional modifica su criterio sobre el mismo problema adoptado en resoluciones anteriores.

\footnotetext{
3 Según el Diario La República, de fecha 4 de setiembre de 2011, habrían desaparecido más de 5000 expedientes, lo que habría causado pérdidas en el Banco de Materiales por un monto superior a los 2500 millones de nuevos soles.
}

70/ QVIPUKAMAVOC | Vol. 23(44) 2015 
El mismo colegiado en el expediente $\mathrm{N}^{\circ} 0007$ 2012-PI/TC de fecha 26 de octubre de 2012, declaró infundada la demanda de inconstitucionalidad de la Ley 29625 e interpretó el artículo 10 de la misma, "en el sentido de que la devolución de "los aportes de sus respectivos empleadores, el Estado y otros en la proporción que les corresponda debidamente actualizados", se destinará a un fondo colectivo y solidario, con el objeto de lograr la satisfacción de la necesidad básica de vivienda de los fonavistas que asílo requieran por su falta de acceso adecuado a este derecho fundamental, en los términos contemplados en los fundamentos 63, 66 y 67 de la presente sentencia”.

Esta decisión del Tribunal Constitucional implica separar la recaudación total por aportes al FONAVI en dos partes: 1) los aportes realizados por cada trabajador dependiente e independiente, que serán devueltos en forma individual y 2) los aportes realizados por los empleadores y otros (aludidos en los literales c, d y e del artículo $2^{\circ}$ de la Ley 22591), que deberán devolverse en forma colectiva, lo que el colegiado denomina: "Fondo colectivo solidario".

\section{¿CÓMO DETERMINAR EL FONDO COLECTIVO Y SOLIDARIO?}

De dos maneras: a) acumulando los aportes realizados al FONAVI de los empleadores y otros señalados en los incisos c, d y e del artículo $2^{\circ}$ de la Ley 22591 ; b) acumulando los aportes realizados al mismo fondo de los trabajadores dependientes e independientes; luego restar estos mes a mes de la recaudación total por aportes al FONAVI. De 1993 a 1998 la legislación antes comentada, facilita este objetivo, como se muestra en la tabla siguiente:

\section{Tabla No 01}

Fondo colectivo y solidario (FCS): 1993-1998

(millones de dólares estadounidenses)

\begin{tabular}{|l|c|c|r|r|r|r|r|}
\hline \multicolumn{1}{|c|}{ Concepto } & \multicolumn{1}{c|}{$\mathbf{1 9 9 3}$} & $\mathbf{1 9 9 4}$ & \multicolumn{1}{|c|}{$\mathbf{1 9 9 5}$} & $\mathbf{1 9 9 6}$ & $\mathbf{1 9 9 7}$ & $\mathbf{1 9 9 8}$ & \multicolumn{1}{c|}{ Total } \\
\hline Recaudación T. & 262,058 & 388,043 & 479,130 & 557,381 & 540,679 & 349,937 & $2,577,229$ \\
\hline Aportes RT $\left(^{*}\right)$ & 229,325 & 129,348 & 89,434 & & & & 448,107 \\
\hline FC S & 32,733 & 258,696 & 389,696 & 557,381 & 540,679 & 349,937 & $2,129,122$ \\
\hline
\end{tabular}

* Aportes realizados por los trabajadores dependientes e independientes.

Fuente: SUNAT, Nota Tributaria de 1992 a 1998, diciembre de cada año.

La recaudación total de enero de 1993 a setiembre de 1998 alcanzó 2577 millones de dólares; restando los aportes realizados por los trabajadores dependientes e independientes ${ }^{4}$ (448 millones de dólares) obtenemos el fondo colectivo y solidario de noviembre de 1993 a setiembre de 1998, correspondiente a 59 meses $^{5}, 2129$ millones de dólares. Considerando los aportes del empleador: $4 \%$ de julio de 1979 a octubre de 1988 , 5\% de noviembre de 1988 a febrero de 1992 y $8 \%$ marzo a diciembre de 1992 y otras, la recaudación por aportes al FONAVI de los empleadores, de julio de 1979 a diciembre de
1992, en 163 meses, habría sido una suma similar a la obtenida en 59 meses; agregando esta suma, el fondo colectivo solidario, aludido en la STC en el expediente $\mathrm{N}^{\circ}$ 0007-2012-PI/TC, sería más de 4 mil millones de dólares. Si a esta suma se añade los aportes realizados por los trabajadores, la deuda pública interna individual y colectiva proveniente de los recursos FONAVI, sería aproximadamente 5 mil millones de dólares, puesto que los trabajadores que accedieron a una vivienda con préstamos hipotecarios lo amortizaron mensualmente.

4 Los trabajadores independientes, por falta de reglamentación de la Ley 26233, a partir de noviembre de 1993 habrían dejado de pagar la contribución al FONAVI. Los empleadores, de enero a octubre de 1993, fueron excluidos de los aportes al mismo fondo.

5 Por Ley 25981, de enero a octubre de 1993, los empleadores fueron excluidos de los aportes al FONAVI. 
La recaudación de enero de 1993 a setiembre de 1998 se presentan, en forma detallada, en las tablas $\mathrm{N}^{\circ} \mathrm{s} 01$ y 02 en nuevos soles y en dólares, respectivamente. Los importes de la tabla $\mathrm{N}^{\circ} 02$ se obtienen dividiendo la recaudación de cada mes de la tabla $\mathrm{N}^{\circ} 01$ entre el tipo de cambio correspondiente de la tabla $\mathrm{N}^{\circ} 03$, para expresar la recaudación total por aportes al FONAVI en dólares estadounidenses y valorar su significación económica en términos de bienes inmuebles y deuda pública interna individual y colectiva, reconocida solo por referéndum; pero de acuerdo con las señales mostradas por la élite gobernante, la mayor parte será recordada como otra deuda pública interna olvidada.

Sumando la recaudación anual mostrada en la tabla $\mathrm{N}^{\circ} 02$ resultan 2577 millones de dólares.

¿Cuántas viviendas de interés social se pudieron construir con 2577 millones de dólares, el monto recaudado por aportes al FONAVI en los últimos 69 de vigencia de mismo?

Antes de contestar esta interrogante cabe recordar una referencia histórica. A mediados de 1989, el costo de una vivienda de dos plantas con jardines exteriores e interiores, área del terreno 400 metros cuadrados, en Magdalena del Mar, era 28 mil dólares financiada con crédito hipotecario amortizable en 15 años; en 1996, siete años después, considerando un incremento de precios de bienes inmuebles en la misma zona promedio anual de $10 \%$, el valor del mismo inmueble habría superado 54 mil dólares.

De otro lado, el penúltimo párrafo del artículo $22^{\circ}$ del Decreto Ley 22591 limita el valor de las vi- viendas construidas con recursos del FONAVI a 360 sueldos mínimos o menos; en diciembre de 1996, la RMV fue S/.215,00 multiplicando por 360 resulta S/.77 400,00; con el tipo de cambio venta del mismo mes y año (S/.2,584 por dólar) equivalen 29954 dólares, el valor de cada vivienda o sumas menores.

Dividiendo 2577 entre 69 resulta un promedio mensual de 37 millones de dólares ${ }^{6}$ y picos; haciendo la misma operación: 37 millones de dólares entre 29954 dólares obtenemos 1245, el número mínimo de viviendas que debió construirse cada mes de 1993 a 1998. Como el literal b) del artículo $22^{\circ}$ de la misma ley, establece que el valor actualizado de la vivienda no exceda 90 veces de la remuneración mensual total (RMT) del adquiriente, lo que implica: RMT x $90=$ 29 954. Resolviendo, la remuneración mensual total máxima para acceder a una vivienda construida con recursos del FONAVI no debía exceder de 332,80 dólares mensuales, equivale 4 veces la remuneración mínima vital de diciembre de 1996. Como los aportantes al FONAVI de menores ingresos son los más necesitados de viviendas de interés social, cuyo costo es menor; con 37 millones de dólares se pudieron construir mensualmente más de 1500 viviendas, en 69 meses más de 103500 viviendas de interés social, de 1993 a 1998, sin contar los reembolsos (amortizaciones) de los que accedieron a una vivienda construida con recursos de FONAVI.

Veinte años después de la creación del FONAVI, fue suprimido sin haber resuelto en parte el problema de acceso a la vivienda de los trabajadores aportantes de menores ingresos. 
Tabla No 02

Recaudación por aportes al FONAVI *

(Miles de Nuevos Soles)

\begin{tabular}{|c|c|c|c|c|c|c|}
\hline Mes & $\mathbf{1 9 9 3}$ & $\mathbf{1 9 9 4}$ & $\mathbf{1 9 9 5}$ & $\mathbf{1 9 9 6}$ & $\mathbf{1 9 9 7}$ & $\mathbf{1 9 9 8}$ \\
\hline Ene & 32,731 & 61,300 & 76,357 & 109,153 & 126,564 & 148,549 \\
\hline Feb & 37,036 & 61,928 & 86,628 & 111,352 & 114,248 & 97,333 \\
\hline Mar & 37,892 & 60,261 & 83,789 & 107,399 & 118,569 & 102,352 \\
\hline Abr & 37,307 & 72,996 & 87,326 & 108,924 & 122,754 & 98,294 \\
\hline May & 38,823 & 81,618 & 88,833 & 109,062 & 120,796 & 99,065 \\
\hline Jun & 40,638 & 68,401 & 90,199 & 112,618 & 123,443 & 100,359 \\
\hline Jul & 43,298 & 70,800 & 86,855 & 111,676 & 120,173 & 100,570 \\
\hline Ago & 49,899 & 75,311 & 91,797 & 126,706 & 181,596 & 153,958 \\
\hline Sep & 49,192 & 70,968 & 94,930 & 108,483 & 103,922 & 102,302 \\
\hline Oct & 50,556 & 71,390 & 97,470 & 107,834 & 97,845 & \\
\hline Nov & 53,973 & 76,351 & 97,814 & 117,278 & 100,348 & \\
\hline Dic & 52,087 & 77,226 & 98,918 & 136,079 & 99,213 & \\
\hline Total & 523,432 & 848,550 & $1,080,916$ & $1,366,564$ & $1,429,471$ & $1,002,782$ \\
\hline
\end{tabular}

* Nota Tributaria: 1992 a 1994 cuadro 4, 1995 cuadro 8, 1996 y 1997 cuadro 10, 1998 cuadro 7.

Fuente: SUNAT, Nota Tributaria de 1992 a 1998, diciembre de cada año.

Elaboración propia.

Tabla No 03

Recaudación por aportes al FONAVI

(Miles de dólares estadounidenses)

\begin{tabular}{|c|c|c|c|c|c|c|}
\hline Mes & $\mathbf{1 9 9 3}$ & $\mathbf{1 9 9 4}$ & $\mathbf{1 9 9 5}$ & $\mathbf{1 9 9 6}$ & $\mathbf{1 9 9 7}$ & $\mathbf{1 9 9 8}$ \\
\hline Ene & 19,141 & 28,119 & 34,866 & 46,349 & 48,215 & 54,156 \\
\hline Feb & 21,043 & 28,407 & 39,376 & 47,303 & 43,374 & 34,836 \\
\hline Mar & 20,706 & 27,770 & 37,075 & 45,585 & 45,015 & 36,502 \\
\hline Abr & 19,431 & 33,484 & 38,640 & 46,096 & 46,113 & 34,844 \\
\hline May & 19,707 & 37,268 & 39,307 & 45,123 & 45,344 & 34,845 \\
\hline Jun & 20,319 & 31,233 & 40,088 & 46,042 & 46,390 & 34,323 \\
\hline Jul & 21,121 & 32,182 & 38,948 & 45,638 & 45,331 & 34,548 \\
\hline Ago & 24,106 & 33,772 & 40,799 & 51,215 & 71,242 & 52,154 \\
\hline Sep & 23,650 & 31,402 & 42,191 & 43,638 & 39,364 & 33,730 \\
\hline Oct & 23,735 & 31,871 & 43,205 & 42,238 & 36,937 & \\
\hline Nov & 24,872 & 34,863 & 42,034 & 45,492 & 36,811 & \\
\hline Dic & 24,227 & 37,671 & 42,600 & 52,662 & 36,543 & \\
\hline Total & 262,058 & 388,043 & 479,130 & 557,381 & 540,679 & 349,937 \\
\hline
\end{tabular}

Fuente: Cifras de la Tabla 02 entre los tipos de cambio de la Tabla 04.

Elaboración propia. 
Tabla No 04

Tipos de cambio venta *

(Nuevos Soles por US \$.1 dólar estadounidense)

\begin{tabular}{|c|c|c|c|c|c|c|}
\hline Mes & $\mathbf{1 9 9 3}$ & $\mathbf{1 9 9 4}$ & $\mathbf{1 9 9 5}$ & $\mathbf{1 9 9 6}$ & $\mathbf{1 9 9 7}$ & $\mathbf{1 9 9 8}$ \\
\hline Ene & 1.71 & 2.18 & 2.19 & 2.355 & 2.625 & 2.743 \\
\hline Feb & 1.76 & 2.18 & 2.20 & 2.354 & 2.634 & 2.794 \\
\hline Mar & 1.83 & 2.17 & 2.26 & 2.356 & 2.634 & 2.804 \\
\hline Abr & 1.92 & 2.18 & 2.26 & 2.363 & 2.662 & 2.821 \\
\hline May & 1.97 & 2.19 & 2.26 & 2.417 & 2.664 & 2.843 \\
\hline Jun & 2.00 & 2.19 & 2.25 & 2.446 & 2.661 & 2.924 \\
\hline Jul & 2.05 & 2.20 & 2.23 & 2.447 & 2.651 & 2.911 \\
\hline Ago & 2.07 & 2.23 & 2.25 & 2.474 & 2.549 & 2.952 \\
\hline Sep & 2.08 & 2.26 & 2.250 & 2.486 & 2.640 & 3.033 \\
\hline Oct & 2.13 & 2.24 & 2.256 & 2.553 & 2.649 & \\
\hline Nov & 2.17 & 2.19 & 2.327 & 2.578 & 2.726 & \\
\hline Dic & 2.15 & 2.05 & 2.322 & 2.584 & 2.715 & \\
\hline
\end{tabular}

* Del 15 de cada mes o día hábil siguiente porque en el Perú los tributos se pagan entre el 10 y 20 de cada mes. Fuente: MSBS - Documento: Tipos de cambio 1930 - 1999

Elaboración propia.

\section{CONCLUSIONES}

1. Los aportes al FONAVI de cuenta propia de los empleadores, según el Tribunal Fiscal no califican como contribución sino como impuesto.

2. Los aportes al FONAVI de los trabajadores, tampoco califican como contribución sino como una imposición arbitraria, sin ningún beneficio para la mayoría de aportantes.

3. Las contribuciones de los trabajadores al FONAVI, según el Tribunal Constitucional, no son impuestos desde el 30 de junio de 1979 hasta el 31 de agosto de 1998.

4. El fondo colectivo y solidario, aludido en la STC en el expediente $\mathrm{N}^{\circ} 0007-2012-\mathrm{PI} / \mathrm{TC}$, sería más de 4 mil millones de dólares. Si a esta suma se añade los aportes realizados por los trabajadores, la deuda pública interna individual y colectiva proveniente de los recursos FONAVI, sería aproximadamente 5 mil millones de dólares.

\section{REFERENCIAS BIBLIOGRÁFICAS}

1. Decreto Ley 22591, del 30 de junio de 1979.

2. Decreto Ley 25520, del 27 de mayo de 1992.

3. Tribunal Fiscal (1997) Dictamen 053 de la RTF JOO N 0523-4-1997, en el Exp. $\mathrm{N}^{\circ}$ 3869-96 (16/05/1997). Recuperado de: https://www. mef.gob.pe/contenidos/tribu_fisc/jurisprude/ acuer_sala/1997/resolucion/523-4-97.pdf

4. Tribunal Constitucional (2007) STC en el expediente $\mathrm{N}^{\circ}$ 03283-2007-PA/TC (03/09/2007). Recuperado de http://www.tc.gob.pe/jurisprudencia/2007/03283-2007-AA.html

5. (2012) STC en el expediente $\mathrm{N}^{\circ} 0007-2012-\mathrm{PI} /$ TC (26/10/2012). Recuperado de: http://www. tc.gob.pe/jurisprudencia/2012/00007-2012-AI. html

6. PICÓN, O.; DÁVILA, S. (2007) La naturaleza jurídica de las contribuciones al FONAVI. Gestión Pública, noviembre de 2007. Recuperado de http://www.gestionpublica.org.pe/plantilla/ rxv5t4/1029474941/enl4ce/2007/novi/revges_66.pdf 